\title{
MENTAL FEATURES OF TOP LEVEL ATHLETES
}

\author{
Florin PELIN ${ }^{1}$, Radu PREDOIU ${ }^{1 *}$, Georgeta MITRACHE ${ }^{1}$, Alexandra PREDOIU ${ }^{1}$ \\ ${ }^{1}$ National University of Physical Education and Sports, Faculty of Physical Education and Sport, Bucharest, \\ Romania \\ *Corresponding author: radu_predoiu@yahoo.com@yahoo.com
}

https://doi.org/10.35189/dpeskj.2020.59.1.1

\begin{abstract}
In the last 50 years, various researchers have investigated the characteristics of the champions, wanting to highlight their personality traits, mental and physical states, the feelings experienced by athletes in the moment when they achieve tremendous performance. The aim of our paper is to identify the level at which physical and mental states are experienced by top athletes when they have achieved remarkable performance. Such information is very important in the self-monitoring process - in competition, self-monitoring enables selfregulation, representing a way of psychological support of top-level athletes. Top-level Romanian athletes from different sports, who won medals at the Olympic Games and World Championships, were investigated. Our research is intended to provide support for athletes who, being aware of the differences between their state at the time $t_{0}$ (top athletes become aware after the self-monitoring process) and the optimal psychophysical state (specific to the moments when they achieve extraordinary performance), can intervene in order to activate or to relax, being more confident, detaching themselves from external factors or controlling their effort. In competition, self-monitoring makes self-adjustment possible (athletes can manage their own states in order to get closer to the psychological and physical condition for success). The constellation of mental and physical states that facilitates the achievement of superior results in competitions inevitably depends on the gender and age of the athletes and on the practiced sports branch (besides the interindividual differences related to each person's unique and original personality).
\end{abstract}

Keywords: top athletes, mental features, psychophysical states, self-monitoring.

\section{Introduction}

In order to achieve a champion's optimal development, we emphasize a metaphorical therapeutic story for coaches, called "The specialist, a gardener" (Predoiu, 2016, p. 91). Thus, the work of a coach resembles that of a gardener who takes care of plants - one plant loves the shade, while another loves the sun, one enjoys a sandy soil and another a clay soil, each requiring the best and appropriate care. Regarding performance sports education in Romania at preuniversity level (to be a great champion, the training process is on long term and multifaceted), it is organized in schools with integrated sports programs or with additional sports programs school sports clubs (Mihăilă \& Paraschiva, 2018).

Over the past decades, various researchers have investigated the characteristics of top athletes, wanting to highlight their personality traits, mental and physical states, feelings experienced in the moment of achieving tremendous performance. We present some of the most relevant findings in this domain since the 1970s.

In 1977, Ravizza, interviewing 20 high-performance male and female athletes (practicing 12 sports), highlighted the following features: total immersion in activity; loss of fear - no fear of 
failure; narrow concentration of attention; no thought about performance; the feeling of being completely in control; effortless performance - without forcing; spatiotemporal disorientation (usually time dilation); perceiving the universe as integrated and unified. Mahoney and Avener (1977) administered a questionnaire to the American gymnasts participating in the 1976 Olympic Games (held in Montreal). They have noticed that high-performance gymnasts are more confident in themselves, think more about gymnastics in everyday activities, are more likely to experience prospective dreams, attribute less the failure to external factors (e.g. referees), experience a little more anxiety before the competition and fewer anxious states when the competition actually begins (compared to gymnasts who recorded weaker performance).

Other researchers (Hall, Church, \& Stone, 1980), investigating weightlifters (Olympic champions), identified a close link between the order in which children were born (within a family) and their motivation for performance. Specifically, the firstborn had a strong need to achieve success, while others were content to avoid failure. The authors showed that both categories of weightlifting athletes (whether born first in a family or not) recorded a relatively low level of trait anxiety.

Garfield and Bennet (1984) identified eight mental and physical states that athletes described as being characteristic of the situations in which they obtained tremendous performance. These feelings are: mentally relaxed (inner calm) - athletes have experienced the sensation of slowing down (subjective time expands with the impression that they have enough time to carry out the right action) and a high degree of concentration; physically relaxed (a sensation of fluid and safe movements); confident/ optimistic - athletes can maintain their balance and self-confidence even during challenges involved in sports activity; focused on the present - there are no thoughts about the past or the future, the body executes the movements automatically, without conscious mental effort; very energetic - there is a state of high energy that appears in the form of feelings like joy or ecstasy, the athlete feels "loaded" or "hot"; extraordinary awareness - athletes are especially aware of their own bodies and those of athletes around the world, with the impression that they know what other athletes want to do and react appropriately; in control - mind and body seem to automatically do exactly what is needed (in the absence of a sense of control); in a cocoon - in their best moments, athletes feel completely detached from the external environment, as in $a$ cocoon, being able to avoid a decrease in concentration and impulsive feelings.

Studying 20 wrestlers (10 practicing Greco-Roman wrestling and 10 freestyle wrestling) who represented the United States at the 1988 Olympic Games, Gould, Eklund and Jackson (1993) highlighted (using a questionnaire) that winning athletes followed a mental plan, were very confident in their own abilities, very focused on the task and emotionally activated at an optimal level. In defeat situations, athletes deviated from mental training strategies, were less attentive and confident and experienced negative thoughts.

Jackson (1996) interviewed 14 male and 14 female elite athletes in order to compare their perceptions with Csikszentmihalyi's description of the optimal states. $80 \%$ of the surveyed athletes confirmed the paradox of control (the sense of control, without having to think about it), 
the fact that they were completely focused on the imminent task and so much involved that the activity seemed spontaneous and automatic to them.

A few years later, Vernacchia et al. (2000) presented their results obtained after the investigation of 15 champions practicing athletics: 4 athletes were medalists at the Olympic Games, 3 held the record in their sports branch, one held two world records and 7 athletes were American champions at athletics. Using the interview (30 minutes), the authors have discovered the following:

- visualization/ guided imagery occupies a very important place in the training process;

- approximately 50\% of athletes adopt the coping strategy (to cope with stress) called religion orientation to overcome injuries in the critical moments of their careers. Orientation towards religion (prayers) refers to the extent to which the athlete appeals to divinity for help in unsafe moments, searching for emotional support, for positive reinterpretation of stressful events, or as a form of active coping with a stressor (religious orientation thus fulfills multiple functions);

- special emphasis is placed on the pleasure of training (which must have fun components) and on maintaining ethics in the training process.

Other studies (Gould et al., 2002), focusing on groups of athletes that practiced various sports, analyzed the athletes participating in the Olympic Games of Atlanta (summer) and Nagano (winter), highlighting the importance of planning and pre-competitive training for situations/ factors with disturbing potential (distractors), as very important variables in achieving superior performance. In the same year, Durand-Bush and Salmela (2002) also talk about the importance of good competition planning and the concentration of athletes on the process (and not on the outcome). We complement this information with the research of Mallett and Hanrahan (2004), who highlight the importance of clearly formulated goals (short, medium and long term), the importance of strong self-confidence (the sport practiced is placed in the center of the inner universe), and with the study conducted by Fallby et al. (2006), who argue the special role of the internal locus of control and a high sense of coherence - individual elite athletes "who perceive their world to be controllable, manageable, and meaningful have more developed mental skills". Closer to the present day, Barker et al. (2012), investigating three former Olympians, mentioned the relevance (for the training process) of the multidimensional, complex experiences and of athletes' abilities to conduct themselves. In the next years, Hansen and Andersen (2014) argue the importance of sensegiving (an element of coaching behavior), which improves the training process of elite athletes in cross-country skiing.

In Romania, Dinţică and Păunescu (2014), studying the mental features of performance athletes (fencers), emphasized the importance of various emotional-affective experiences (positive and negative), of the emotional stability and attitudes - which depend on the selfassessment that each athlete makes. Also, Predoiu et al. (2018) presented the strengths and weaknesses of the members of the Romanian Greco-Roman and freestyle wrestling Olympic team. The strengths highlighted (for both male and female athletes) were vigilance, attention concentration (speed of answers), fast perceptive inspection of the environment and resistance to disruptive factors. 
Last but not least, we present how Michael Phelps (the holder of a statistical record - 23 gold medals won at the Olympic Games) copes with psychological pressure during the competition. The athlete has told The Washington Post that he visualizes a plan for each scenario - if the costume breaks or the glasses are broken; his coach continued, explaining: "He will see exactly the perfect race. And he will see it both from the outside (from the perspective of a spectator sitting in the tribune) and from the inside - from the water. And then he will face different scenarios: If things do not work well?" (Lebowitz, cited by Predoiu, 2018, p. 131). The athlete, therefore, has all the scenarios prepared and has specific behavioral modalities, depending on the situation. One of the current issues at international level is how elite athletes cope with depression. Among the most used coping strategies (emphasized by the participants) were seeking professional help and social support (Lebrun \& MacNamara, 2019).

The purpose of our paper is to highlight the level at which physical and mental states are experienced by top athletes when they have achieved remarkable performance, very important data in the self-monitoring process (self-monitoring enables self-regulation, representing a way of psychological support of top-level athletes).

\section{Methodology}

\section{Participants}

This is a descriptive research that includes two Romanian top-level athletes. The sports performances of the two great champions are (we mention that the informed written consent was obtained):

- Athletics (athlete's gender: woman) - she was designated the world's best athlete (1999) and Europe's best athlete, gold medal (5000 meters) and bronze (1500 meters) at the Olympic Games in Sydney (2000), silver medal (1500 meters) at the Olympic Games in Atlanta, multiple world champion (Athens and Paris - 1997, Sevilla and Maebashi - 1999, Edmonton - 2001) and European champion (Valencia - 1998 and Ghent - 2000, at 3000 meters).

- Tennis (athlete's gender: man) - he won the first Olympic medal in the history of Romanian tennis in Rio de Janeiro, in 2016 (along with his teammate conquered the silver at the Olympic Games), finalist in the Champions Tournament, semifinalist at Roland Garros and Wimbledon, victories (ranked $1^{\text {st }}$ in doubles) at the ATP World Tour Masters 1000 tournaments.

\section{Instruments}

In our study, we used two opinion questionnaires. The first questionnaire was adapted by us, starting from the ideas and the research of Ravizza (1977), Garfield and Bennet (1984) - see the Introduction part of the paper. Thus, top athletes were presented a series of mental and physical states (highlighted in the Results section of the paper) and were asked to check to what extent/ at what level they experienced the states described when they achieved peak sports performance. In addition (the second questionnaire), we offered a series of attributes for the athletes to select the 
ones facilitating the achievement of superior performance in competitions. The top athletes were asked to identify "Which of the cognitive/intellectual, psychomotor and personality characteristics facilitated your exceptional performance as a professional athlete?" The attributes analyzed were as follows: attention distribution, speed and distance estimation, combativeness, critical thinking, patience, attention concentration, intrinsic motivation, self-control, resistance to mental fatigue, self-confidence and spatial orientation. We underline that all the characteristics specified are important for athletes in competitions, but our goal was to obtain a more nuanced/ accurate map of the phenomenon (directly from the top athletes), depending on the practiced sport.

\section{Procedure}

The top athletes completed the questionnaires from May to June 2018. For the first questionnaire, the briefing was as follows: "On a scale from 1 to 10 , where 1 means not at all and 10 represents a lot (5 means so and so/ moderate), please select the appropriate number for each situation. Please specify to what extent you felt/ experienced in competition, when you obtained the best sports performance, the states described below". For the second questionnaire, the briefing was as follows: "Below you have a questionnaire that appears in the form of a table. Both horizontally and vertically, there are 11 terms (in the same order). Follow the lines like you are reading - horizontally from left to right and top to bottom. Taking the first term - attention distribution - consider whether this feature has made it easier for you to achieve exceptional performance by choosing successively between this term and the other 10 terms on the first line of the table. Choose between attention distribution and speed and distance estimation, then between attention distribution and combativeness, attention distribution and critical thinking, etc. After completing the first row, continue with the second row and so on until the last row of the table, choosing the feature you consider the most important. Remember that there are two attributes in each space from which you have to select one, according to its importance (you have felt it is more important in competition)". After calculating frequencies, the features perceived as having the greatest importance in achieving exceptional sports performance were highlighted.

\section{Results}

We present the psychophysical states experienced by the Olympic and World female champion when she achieved remarkable sport performance - Figure 1 (informed written consent was obtained). 


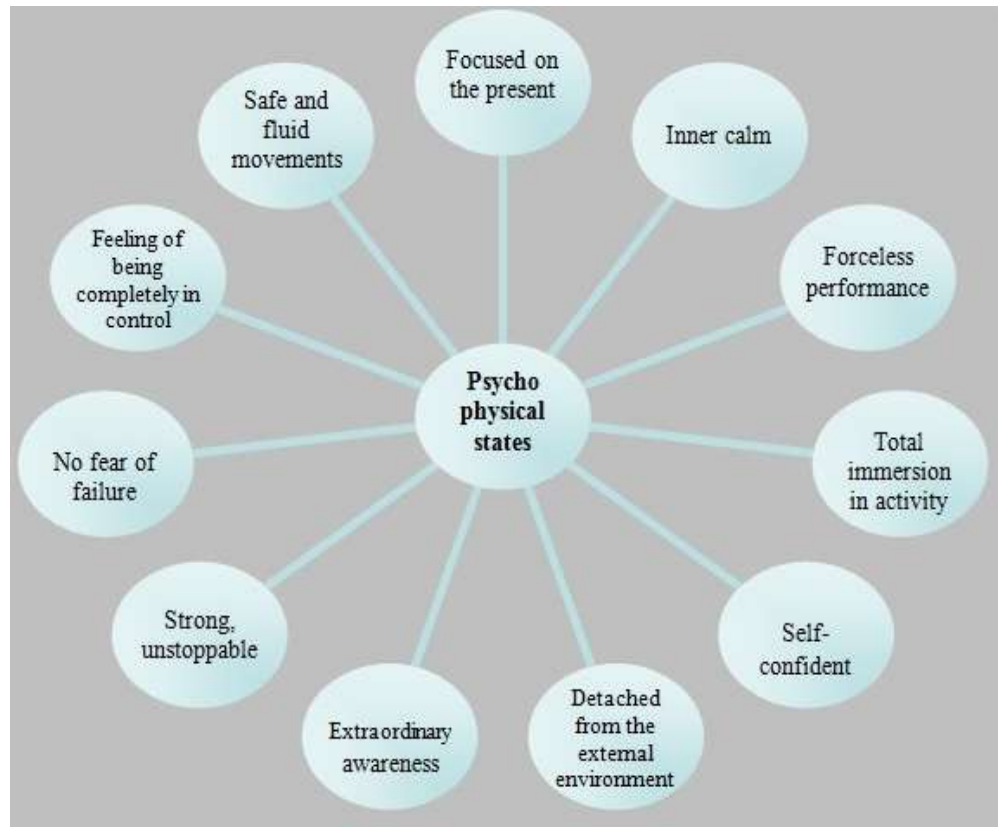

Figure 1. Psychophysical states experienced when high performance was achieved

We mention that all states were felt at a high level of intensity (received a maximum score) during the competition: focused on the present, inner calm, forceless performance, total immersion in activity, self-confident, detached from the external environment, extraordinary awareness, strong, unstoppable, no fear of failure, feeling of being completely in control, safe and fluid movements (physically relaxed). The synergic action of these phenomena is highlighted, objectified in the exceptional sports result. We add to these aspects the importance that the Romanian athlete gives to the space orientation ability and to self-confidence.

Also, we were interested in finding out what a finalist in the Champions Tournament, an athlete ranked among the world's top 7 tennis players (in doubles) feels and thinks on the field. The results, which are of interest for athletes and specialists, aspiring to a medal at the Olympics (but not only) are presented below.

Table 1. Mental and physical states experienced in the case of an extraordinary performance

\begin{tabular}{lllllllllll}
\hline Mental and physical states & \multicolumn{11}{c}{ Marks } \\
\hline Focused on the present, on each point (without effort) & 1 & 2 & 3 & 4 & 5 & 6 & 7 & 8 & 9 & $\mathbf{1 0}$ \\
Total immersion in activity (during the match) & 1 & 2 & 3 & 4 & 5 & 6 & 7 & 8 & 9 & $\mathbf{1 0}$ \\
No thought about performance & 1 & 2 & 3 & 4 & $\mathbf{5}$ & 6 & 7 & 8 & 9 & 10 \\
Loss of fear - no fear of failure & 1 & 2 & 3 & 4 & 5 & 6 & 7 & 8 & 9 & $\mathbf{1 0}$ \\
Mentally relaxed (inner calm) & 1 & 2 & $\mathbf{3}$ & 4 & 5 & 6 & 7 & 8 & 9 & 10 \\
Physically relaxed (fluid and safe movements) & 1 & 2 & 3 & 4 & 5 & 6 & 7 & 8 & 9 & 10 \\
\hline
\end{tabular}




\begin{tabular}{|c|c|c|c|c|c|c|c|c|c|c|}
\hline The feeling of being completely in control & 1 & 2 & 3 & 4 & 5 & 6 & 7 & 8 & 9 & 10 \\
\hline The mind and body automatically do exactly what is needed & 1 & 2 & 3 & 4 & 5 & 6 & 7 & 8 & 9 & 10 \\
\hline Effortless performance - without forcing & 1 & 2 & 3 & 4 & 5 & 6 & 7 & 8 & 9 & 10 \\
\hline Confident in one's own capacity of performance & 1 & 2 & 3 & 4 & 5 & 6 & 7 & 8 & 9 & 10 \\
\hline Strong, unstoppable (a feeling that occurs automatically) & 1 & 2 & 3 & 4 & 5 & 6 & 7 & 8 & 9 & 10 \\
\hline In a "cocoon" (detached from the external environment) & 1 & 2 & 3 & 4 & 5 & 6 & 7 & 8 & 9 & 10 \\
\hline Time expansion (enough time to hit the ball) & 1 & 2 & 3 & 4 & 5 & 6 & 7 & 8 & 9 & 10 \\
\hline $\begin{array}{l}\text { Outstanding awareness (of one's own body and the } \\
\text { opponents') }\end{array}$ & 1 & 2 & 3 & 4 & 5 & 6 & 7 & 8 & 9 & 10 \\
\hline
\end{tabular}

We can notice a total immersion in activity during the match, the athlete having great confidence in his ability to perform and feeling (automatically) strong, unstoppable. The Romanian champion does not feel the fear of failure, he can focus on the present, on the task - on every point, feeling he has enough time to stand and hit the ball. At the same time, he is in contact with his own body (self-monitoring) and displays a high level of awareness (feels he can anticipate what the opponents are about to do next). In general, the mind and the body appear to do exactly what is needed, the performance being achieved without too much effort. The athlete thinks about the outcome but does not anticipate, he is much involved in the activity but keeps in touch with the surrounding reality/ the external environment. Also, the tennis player is more activated than relaxed (psychophysically) when he records his best sports performances. Further, we wanted to highlight the cognitive/ intellectual, psychomotor and personality characteristics that made it possible for him to achieve exceptional performance as a professional tennis player. The champion of Barcelona, Madrid, Stuttgart, Hamburg, Vienna, Vina del Mar and Bucharest mentions the importance of the following dimensions (Figure 2):

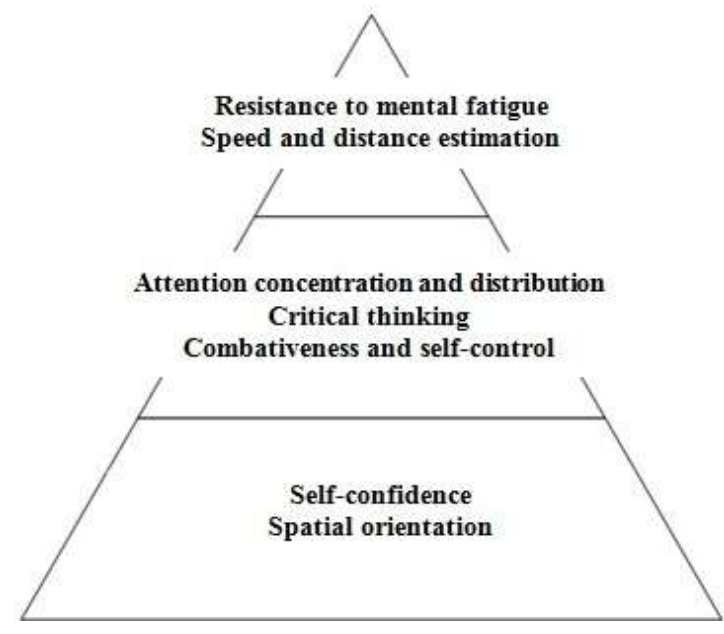

Figure 2. Dimensions that enable the achievement of exceptional performance as a professional tennis player 
The peak of the pyramid is represented by the dimensions to which the champion gives the greatest importance. Of course, all of the coordinates mentioned are important (along with other psychological phenomena such as motivation, perseverance, observation, etc.), our aim being to provide a more nuanced picture of the priority elements in the training process. Specialists, developing phenomena such as resistance to mental fatigue, speed and distance estimation, attention concentration and distribution, will strengthen the athletes' confidence in their own abilities, creating the prerequisites for great performance.

\section{Conclusion}

In the case of the Olympic and World athletics champion, the following states were felt at $a$ high level of intensity during the competition: focused on the present, inner calm, forceless performance (without too much effort), self-confident, detached from the external environment (in a "cocoon"), extraordinary awareness (of her own body and the opponent's actions), strong, unstoppable, total immersion in activity (during the race), no fear of failure, feeling entirely in control, safe and fluid movements (physically relaxed). The synergic action of these phenomena is highlighted, objectified in the exceptional sports result. We also mention the special importance that the Romanian athlete gives to the space orientation ability and to selfconfidence. Self-confidence is a mental phenomenon that is directly proportional with the ability to control one's own body issues - in this regard, we mention the relaxation techniques that play a very important role.

In the case of the Romanian tennis player, we can see a total immersion in the match, the athlete having great confidence in his ability to obtain success and feeling (automatically) strong, unstoppable. He does not feel the fear of failure, can concentrate on the present, on the task (on each point), feeling he has enough time to stand and hit the ball. At the same time, he is in contact with his own body and displays a high level of awareness (feels he can anticipate what the opponents will do next). In general, the mind and body seem to do exactly the right thing, the success coming without too much effort. The athlete thinks about the outcome but does not anticipate, is much involved in the game but keeps in touch with the surrounding reality. Also, the tennis player is more activated than relaxed (psychophysically) when he achieves his best performances.

Our paper is intended to provide support for athletes who, being aware of the differences between their state in the moment $t_{0}$ (top athletes become aware after the self-monitoring process) and the optimal psychophysical state (specific to the moments when they achieve extraordinary performance), can intervene in order to activate or to relax, being more confident, detaching themselves from external factors or controlling the effort. In competition, selfmonitoring makes self-adjustment possible (athletes can manage their own states in order to get closer to the psychological and physical condition for success), representing a way of psychological support of top-level athletes.

Each top athlete who uses the presented questionnaire (see Table 1) can become aware of his or her own constellation of mental and physical states that facilitated the achievement of superior 
results in competitions, an essential step for subsequent self-adjustments. Such a constellation/ state matrix specific to each individual athlete inevitably depends on the gender and age of the athlete and on the practiced sports branch (besides the interindividual differences related to each person's unique and original personality).

As Silva, Schultz, Haslam and Murray (1981) stated, the understanding of the psyche of top athletes is at an embryonic stage. In the next decades, few things changed from that statement, due to the inconsistency generated by the use of different assessment tools and the variability concerning what an elite athlete means. At the moment, steps are being taken to get to know the champions' psychological system and further investigations are needed to provide a clearer light on the states experienced by top athletes, according to gender, age and the practiced sports branch.

\section{Authors' Contributions}

All authors have equally contributed to this study.

\section{References}

Barker, D., Barker-Ruchti, N., Rynne, S. B., \& Lee, J. (2012). Olympism as education: Analysing the learning experiences of elite athletes. Educational Review, 64, 369-384. https://doi.org/10.1080/00131911.2012.665846

Dinţică, G., \& Păunescu, M. (2014). The aggression profile in performance fencing. Procedia Social and Behavioral Sciences, 117, 34-37. https://doi.org/10.1016/j.sbspro.2014.02.174

Durand-Bush, N., \& Salmela, J. H. (2002). The development and maintenance of expert athletic performance: Perceptions of World and Olympic champions. Journal of Applied Sport Psychology, 14(3), 154-171. https://doi.org/10.1080/10413200290103473

Fallby, J., Hassmén, P., Kenttä G., \& Durand-Bush, N. (2006). Relationship between locus of control, sense of coherence, and mental skills in Swedish elite athletes. International Journal of Sport and Exercise Psychology, 4(2), 111-120. https://doi.org/10.1080/1612197X.2006.9671788

Garfield, C. A., \& Bennett, H. Z. (1984). Peak performance: Mental training techniques of the world's greatest athletes. New York: Warner Bros.

Gould, D., Eklund, E. C., \& Jackson, S. A. (1993). Coping strategies used by U.S. Olympic wrestlers. Research Quarterly for Exercise and Sport, 64, 83-93. DOI:10.1080/02701367.1993.10608782

Gould, D., Greenleaf, C., Chung, Y., \& Guinan, D. (2002). A survey of U.S. Altanta and Nagano Olympians: Variables perceived to influence performance. Research Quarterly for Exercise and Sport, 67, 76-90. DOI: 10.1080/02701367.2002.10609006

Hall, E. G., Church, G., \& Stone, M. (1980). Relationship of birth order to selected personality characteristics of nationally ranked Olympic weightlifters. Perceptual and Motor Skills, 73(2), 175-186. https://doi.org/10.2466/pms.1980.51.3.971

Hansen, P. O., \& Andersen, S. S. (2014). Coaching elite athletes: How coaches stimulate elite athletes' reflection. Sports Coaching Review, 3(1), 17-32. https://doi.org/10.1080/21640629.2014.901712 
Jackson, S. A. (1996). Toward a conceptual understanding to the flow experience in elite athletes. Research Quarterly for Exercise and Sport, 67, 76-90. https://doi.org/10.1080/02701367.1996.10607928

Lebrun, F., \& MacNamara, A. (2019). Elite athletes coping with depression: A qualitative study. $\begin{array}{lllll}\text { Journal of Clinical Sport } & \text { Psychology, } & \text { 13(3), }\end{array}$ DOI: https://doi.org/10.1123/jcsp.2018-0072

Mahoney, M. J., \& Avener, M. (1977). Psychology of the elite athlete: An exploratory study. Cognitive Therapy and Research, 7, 135-141. https://doi.org/10.1007/BF01173634

Mallett, C. J., \& Hanrahan, S. J. (2004). Elite athletes: Why does the "fire" burn so brightly? Psychology of Sport and Exercise, 5(2), 183-200. https://doi.org/10.1016/S14690292(02)00043-2

Mihăilă, C. V., \& Paraschiva, G. A. (2019). An approach to school sports clubs as learning organizations. The European Proceedings of Social \& Behavioural Sciences EpSBS, LV, 453464. DOI:10.15405/epsbs.2019.02.57

Predoiu, R. (2016). Psihologia sportului. Maximizarea performanţei sportive [Sport psychology. Maximizing sports performance]. Iaşi: Polirom.

Predoiu, R. (2018). In mintea campionilor [Inside the minds of the champions]. Bucharest: Discobolul.

Predoiu, A., Predoiu, R., Pelin, F., Mitrache, G., Grigore, V., \& Ozarchevici, C. (2018). Intellectual and psychomotor strengths and weaknesses in the case of athletes - members of the Romanian Graeco-roman and Freestyle Wrestling Olympic Team. Discobolul - Physical Education, Sport and Kinetotherapy Journal, 54, 11-17. Retrieved from https://discobolulunefs.ro/wp-content/uploads/2019/04/Discobolul-No.-54-December2018.pdf

Ravizza, K. (1977). A subjective study of the athlete's greatest moment in sport. In Proceedings of the Canadian Psychomotor Symposium, Psychomotor Learning and Sport Psychology Symposium (pp. 399-404). Toronto, Canada: Coaching Association of Canada.

Silva, J. M., Schultz, B., Haslam, R., \& Murray, D. (1981). A psychophysiological assessment of elite wrestlers. Research Quarterly for Exercise and Sport, 52, 348-358. DOI: 10.1080/02701367.1981.10607882

Vernacchia, R., McGuire, R. T., Reardon, J. P., \& Templin, D. P. (2000). Psychosocial characteristics of Olympic track and field athletes. International Journal of Sport Psychology, 31, 5-23. Retrieved from https://www.coursehero.com/file/7869936/The-PsychosocialCharacteristics-of-Olympic-Track-and-Field-Athletes/ 